\title{
A IMPLANTAÇÃO DA LOGÍSTICA DE UMA EMPRESA DENTRO DE UMA ZPE: ESTUDO DE CASO CSP*
}

Juliane Medeiros Ferraz ${ }^{1}$ Katarina Crisostomo ${ }^{2}$

\section{Resumo}

Este estudo tem como objetivo apresentar as etapas, os desafios e melhorias na implantação da área da logística da Companhia Siderúrgica do Pecém (CSP) na primeira Zona de Processamento de Exportação (ZPE) do país que está localizada no estado do Ceará e tem a siderúrgica CSP como a primeira empresa a se instalar nessa área de livre comércio com o exterior. Nesse contexto a logística tem um papel importante e fundamental no planejamento e controle minucioso dos fluxos de entrada e saída de materiais e produtos cumprindo todas as legislações federais e estaduais de uma ZPE. O estudo é realizado através da análise dos conceitos logísticos de uma siderúrgica e das normas e portarias que regem uma ZPE. Os resultados alcançados estão pautados nas sugestões e alterações das disposições legais e na integração entre os sistemas controlados pela Receita Federal com o sistema da CSP. O estudo tem como conclusão que todas as melhorias que foram propostas e alcançadas nessa implantação pioneira, proporcionaram maior eficiência e agilidade nos processos de controle aduaneiro da ZPE voltados para uma siderúrgica, mantendo continuamente a interação entre todas as entidades legais sem impactar a dinâmica operacional da siderúrgica, agregando grande valor para a CSP.

Palavras-chave: ZPE; Logística; Legislação; Sistemas.

\section{LOGISTICS IMPLEMENTATION OF A STEEL COMPANY AT ZPE: CASE STUDY AT CSP}

\section{Abstract}

This study aim to present the steps, challenges and improvements in the implementation of the logistics area of Companhia Siderúrgica do Pecém (CSP) in the first Zona de Processamento de Exportação (ZPE) in Brazil which is located in the state of Ceará and has CSP as the first company to settle in the area of free trade with foreign countries. In this context, logistics has an important and crucial role in planning and detailed control of the inbound and outbound streams of materials and products complying with all federal and state laws of ZPE. The study is carried out by analyzing the logistics concepts of steel making and the rules and ordinances governing the ZPE. The results achieved are guided by the suggestions and amendments to the legal provisions and the integration between the systems controlled by the Receita Federal with the CSP's system. The study has concluded that all the improvements that have been proposed and achieved this pioneering deployment, provided greater efficiency and agility in customs control procedures of ZPE for application in steelworks, continuously keeping the interaction between all legal entities without impacting the operational dynamics steelworks, adding great value to CSP.

Keywords: ZPE; Logistics; Laws; Systems.

1 Administradora de Empresas, Pós Graduada em Gestão Industrial, Analista de Logística, Dpto de Logística, CSP, São Gonçalo do Amarante, Ceará, Brasil.

2 Engenheira de Produção Mecânica, Pós Graduada em Eng. de Produção, Coord. Planej. Logístico, Dpto de Logística, CSP, São Gonçalo do Amarante, Ceará, Brasil. 


\section{INTRODUÇÃO}

As Zonas de Processamento de Exportação (ZPE) são distritos industriais incentivados e alfandegados destinadas à instalação de empresas voltadas para a produção de bens a serem comercializados em sua maior parte no exterior. Para fins aduaneiros, as ZPEs são consideradas como zonas primárias. A principal vantagem para os empreendimentos instalados em ZPE é a suspensão da incidência de alguns tributos federais na aquisição de bens e serviços.

O presente estudo destaca a CSP como a primeira empresa a se instalar nessa área alfandegada, sob a qual a Logística precisou estudar uma estratégia de implantação para atender as normas legais da ZPE garantindo que o fluxo de materiais não sofra impactos devido todo o perímetro da empresa, principalmente os seus portões (Portão de Despacho, Portão de Transferência, Portão Administrativo e Portão de Placas), estarem sob a guarda da ZPE e RFB. Devido a isso, a Logística da CSP é pioneira em implantar uma operação diferenciada à logística de outras siderúrgicas.

O fluxo diário total do transporte terrestre de materiais e produtos da CSP é de cerca de 335 (trezentos e trinta e cinco) veículos entrando e saindo pelos portões da ZPE. Desse total, $32 \%$ (trinta e dois por cento) é representado pelo grupo de matérias primas de grandes volumes (ex: granéis de calcário, dolomita, sílica, etc), $52 \%$ (cinquenta e dois por cento) por subprodutos (ex: escória, lama, etc) e o restante 16\% (dezesseis por cento) por materiais esporádicos.

Foi tomado como base desse estudo, o grupo de entrada de matérias primas de grandes volumes, por ter sido o primeiro fluxo logístico a entrar em operação na CSP. Nesse contexto, o trabalho tem como objetivo apresentar os conceitos de uma ZPE e a condução do pioneirismo da implantação de uma área logística dentro de uma ZPE. Não foi considerado no estudo o fluxo de carvão e minério pois o transporte é feito via correia transportadora, ou seja, não passa pelos portões da ZPE.

A seguir são apresentados os procedimentos de ZPE, para realizar o controle aduaneiro.

\subsection{Etapas de Controle Aduaneiro da ZPE}

Conforme o ADE (Ato Declaratório Executivo) $n^{\circ} 2$, que especifica os requisitos técnicos, formais e prazos para implantação de sistema informatizado de controle aduaneiro, são estabelecidas as seguintes regras aduaneiras de acesso de pessoas, veículos e cargas à uma área alfandegada da ZPE:

- Credenciamento de acesso de Pessoas e Veículos;

- Cadastro da carga;

- $\quad$ TLMN (Termo de Liberação de Mercadoria Nacional);

- RTM (Relação de Transferência de Mercadoria);

- Agendamento de entrada ou saída da carga;

- Conclusão de trânsito da RTM;

- Retificações da carga.

A Portaria 38 estabelece que o acesso de pessoas e veículos a CSP, por estar dentro de uma ZPE, dá-se mediante a obrigatoriedade do cadastro dos dados pessoais e documentos no sistema da ZPE, SICA (Sistema de Controle Aduaneiro). O cadastro é válido por três anos e deve ser mantido atualizado sempre que necessário. Após isto, para acessar as áreas internas da CSP deve ser também solicitado o acesso indicando o período e o motivo da execução da atividade na empresa. Tanto o cadastro quanto o acesso são submetidos à aprovação da ZPE. 
Todo material para acessar uma ZPE deve possuir o "Cadastro da Carga" que contempla o cadastro dos dados da Nota fiscal no sistema SICA e o upload dos arquivos XML e PDF da Nota Fiscal. Uma vez que os dados transcritos estejam corretos, o sistema da ZPE gera o código da carga referente a Nota Fiscal.

A empresa instalada na ZPE, deve apresentar, com no mínimo 2 (dois) dias antes da chegada da carga, o pedido formal de liberação da mercadoria à Alfândega da RFB, anexando a Nota Fiscal Eletrônica que acoberta a operação. A RFB irá analisar as informações documentais e emitirá o TLMN (Termo de Liberação de Mercadoria Nacional).

Com a emissão do TLMN, a empresa deve solicitar a aprovação da RTM (Relação de Transferência de Mercadoria), conforme disposto no art. 11 da Instrução Normativa RFB $n^{\circ}$ 952, de 2009, para a transferência da carga entre ZPE e a empresa. Considerando os dados do cadastro da carga, a ZPE analisa e aprova a RTM.

Após aprovado o TLMN e RTM, a empresa deve realizar o agendamento de entrada do veículo indicando o código da carga a ser transportada, ou seja, a Nota Fiscal anteriormente cadastrada, o motorista e o veículo que estão conduzindo a carga, a data prevista e o motivo. Essa etapa é essencial, pois toda entrada e saída pelos portões passa por controle de liberação da ZPE.

Quando o veículo realiza a saída da empresa, é necessário que a logística informe no sistema SICA a conclusão do trânsito da RTM. Após isto, a ZPE identifica via sistema SICA se houve divergência das informações declaradas inicialmente na RTM e solicita a retificação da carga.

\section{MATERIAIS E MÉTODOS}

Foram utilizados para o estudo, a legislação básica das ZPE's no Brasil tais quais: a Lei $n^{\circ} 11.508 / 2007$, Lei $n^{\circ} 11.732 / 2008$, o Decreto $n^{\circ} 6.814 / 2009$, a Instrução Normativa RFB n 952/2009, Portaria RFB n 3.518/2011, a Portaria ALF/PCE $n^{\circ}$ $38 / 2015$. Foram utilizados também os sistemas informatizados da ZPE, CSP, RFB e SEFAZ.

\section{RESULTADOS E DISCUSSÃO}

Através das análises normativas que envolve a ZPE, a Logística sugeriu melhorias e alterações legais que proporcionavam maior agilidade nos processos de controle aduaneiro sem prejudicar o fluxo contínuo de recebimento de materiais e saída de produtos que envolve uma siderúrgica, além de propor interações sistêmicas.

\subsection{Otimização do processo}

O grupo de matérias primas de grandes volumes, objeto deste estudo, tem cerca de 108 (cento e oito) veículos entrando e saindo por dia, todos passando pelos Portões de Despacho e Portões de Transferência da ZPE. Considerando que cada veículo transportará uma Nota Fiscal, isto resultaria na solicitação de 108 (cento e oito) TLMNs (Termo de Liberação de Mercadoria Nacional) por dia.

Visando uma melhoria no fluxo de processos, foi proposto assim, a utilização do conceito de Nota Fiscal de Venda para Entrega Futura. Deste modo, cada fornecedor deve emitir uma Nota Fiscal considerando o volume mensal a ser entregue. Este tipo de operação está disciplinado nos artigos 705 a 707 do Decreto 24.569/97. Nessas 
condições, é emitida uma Nota Fiscal denominada "mãe", que é utilizada na solicitação do TLMN à Receita Federal do Brasil.

Sendo assim, conforme tabela 1, foi feito um comparativo entre o cenário de uma operação normal e o cenário de uma operação com a proposta de otimização da quantidade de TLMN a ser aprovada pela RFB.

Tabela 1. Cenários da quantidade de TLMN a solicitar a RFB

\begin{tabular}{lccc} 
Origem & $\begin{array}{c}1^{\circ} \text { Cenário: Sem } \\
\text { Entrega Futura } \\
\text { TLMN/dia }\end{array}$ & $\begin{array}{c}1^{\circ} \text { Cenário: Sem } \\
\text { Entrega Futura } \\
\text { TLMN/mês }\end{array}$ & $\begin{array}{c}2^{\circ} \text { Cenário: Com } \\
\text { Entrega Futura } \\
\text { TLMN/mês }\end{array}$ \\
\hline Ceará & 92 & 2760 & 5 \\
\hline Sergipe & 8 & 240 & 2 \\
\hline Bahia & 4 & 120 & 1 \\
\hline Espírito Santo & 2 & 60 & 1 \\
\hline Minas Gerais & 1 & 30 & 1 \\
\hline Rio de Janeiro & 1 & 30 & 11 \\
\hline \multicolumn{1}{c}{ TOTAL } & 108 & 3240 & \\
\hline
\end{tabular}

O primeiro cenário indica que 1 NF corresponde a 1 TLMN por veículo, ou seja, 108 (cento e oito) solicitações de TLMN por dia, o que equivale a 3.240 (três mil, duzentos e quarenta) solicitações por mês.

O segundo cenário indica que 1 NF Entrega Futura corresponde a 1 TLMN por um lote de entrega por mês, ou seja, 11 (onze) solicitações de TLMN por mês. Deste modo, obtém-se uma redução de 3.229 (três mil e duzentos e vinte e nove) solicitações por mês.

Com relação à RTM, o controle de saldo da mercadoria da NF "mãe" será feito através da aferição do peso da balança da ZPE.

Após a transferência completa da mercadoria para a CSP, ou seja, após a entrega da última remessa da NF "mãe", a logística informa a conclusão do trânsito da RTM no sistema.

Em caso de divergência de peso, fora da tolerância estabelecida, a CSP emite uma NF de devolução da quantidade a menor ou solicita uma NF complementar do Fornecedor em caso de quantidade a maior. Feito isto, a Logística retifica a RTM para aprovação da ZPE.

Durante o estudo de melhorias no processo foram também levantadas as melhorias para execução das atividades acima de forma automatizada entre os sistemas da CSP e ZPE.

\subsection{Integração de Sistemas}

Para aumentar a confiabilidade dos dados e reduzir tempo operacional, foi proposto também implantar um sistema de integração dos sistemas da CSP (SAP, MES, EDI) e da ZPE (SICA), denominado SCZ.

A figura 1 demonstra o esquema de integração dos sistemas, onde o processo se inicia com o recebimento do arquivo da Nota Fiscal. Para isso, foi desenvolvido o sistema EDI (Eletronic Data Interchange) para realizar as críticas das informações declaradas na Nota Fiscal em relação ao Pedido de Compra. Confirmados que os dados estão corretos, o sistema SCZ recebe as informações e envia ao sistema SICA para realizar o Cadastro de Carga e solicitar o TLMN e RTM automaticamente.

As aprovações da RFB e ZPE que anteriormente eram realizadas mediante documento físico, foi substituído por assinatura digital. 
Para realizar o agendamento no sistema SICA, o transportador informa o código da carga referente a NF "mãe" e apenas anexa o XML da NF "filha", permitindo que o sistema SCZ realize o controle de saldo da NF "mãe".

Para realizar a aferição do peso da carga pela balança da ZPE, também foi implantado o sistema de integração das balanças com o sistema SCZ.

Após a segunda pesagem na saída do veículo, o sistema SCZ transmite o peso para o sistema SAP e transmite a informação para a Logística gerar a MIGO (transação SAP de recebimento físico). Esta por sua vez, transmite a informação para o SCZ que finaliza o trânsito no sistema SICA.

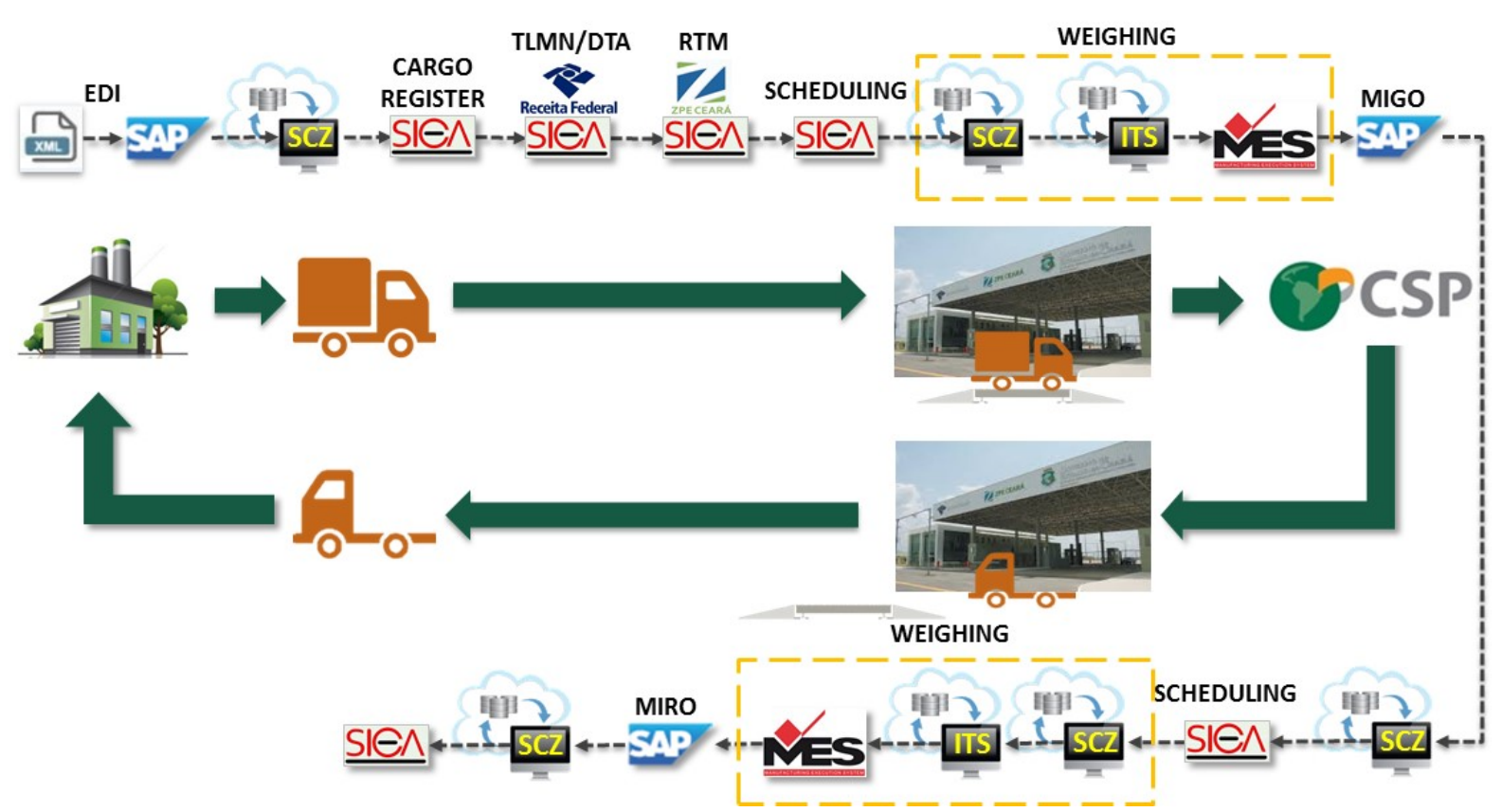

Figura 1. Esquema de integração de sistemas

Em resumo, pode-se destacar que os sistemas implantados para atender a Logística da CSP, atende as normas de ZPE, a modelagem da operação dos portões, KPI's em todo ciclo operacional, interação com ZPE, RFB e SEFAZ (Secretaria da Fazenda). É importante ressaltar que os conceitos levantados e resultados encontrados também atendem a entrada dos demais grupos de materiais e a saída de produtos.

\section{CONCLUSÃO}

Como apresentado neste trabalho, a legislação de ZPE possui regras de controle aduaneiro que demanda tempo de análise e aprovação por parte dos órgãos competentes, visto a necessidade de monitorar os impostos suspensos da operação. A agilidade no recebimento de materiais é ponto fundamental para o bom andamento dos processos siderúrgicos que envolve as áreas de produção.

As propostas sugeridas pela Logística da CSP visaram reduzir os tempos de entrada e saída de veículos para carregamento e descarregamento de materiais e produtos. Esse fator seria potencial causa de problemas operacionais, como acúmulo de processos a serem liberados, demora nos acessos de veículos a área industrial, excesso de veículo em espera para entrada e saída na ZPE e, consequentemente, insatisfação dos clientes internos e externos da logística.

Como pode-se observar, o planejamento e controle é essencial para uma empresa que está instalada em uma ZPE. Assim ao final da modelagem operacional que 
envolve novas portarias e normas que foram baixadas para viabilizar o processo da siderúrgica, constatou-se que a logística da CSP trabalhou para a otimização de seus processos buscando melhoria nos serviços prestados sem se afastar do cumprimento legal das regras de uma Zona de Processamento de Exportação.

Com a implementação das propostas de melhorias de processo e sistema levantadas nesse estudo, houve redução do tempo de espera dos veículos nos portões da ZPE, com as liberações documentais realizadas via sistema, houve redução de erros manuais e do tempo de atividade operacional com a automatização das atividades.

Por fim, a Logística da CSP, como pioneira na implantação de uma siderúrgica em uma ZPE, visa elevar continuamente o nível de serviço e a qualidade das informações prestadas sem impactar as áreas operacionais da siderúrgica, bem como proporcionar maior segurança para a companhia, fornecedores e principalmente os órgãos que controlam a legislação da ZPE.

\section{Agradecimentos}

Agradecemos ao apoio e contribuição da equipe de Logística da CSP: Cláudia Carvalho, coordenadora de Comércio Exterior, Kátia Barros, analista de Logística, e Maytê Coelho, especialista em logística regulatória.

\section{REFERÊNCIAS}

1 Ato Declaratório Executivo Coana / Cotec $\mathrm{n}^{\circ} 2$, de 26 de setembro de 2003

2 Decreto $n^{\circ} 6.814 / 2007$. [acesso em 15 set. 2015]. Disponível em: http://www. planalto. gov.br/ccivil_03/_Ato2007-2010/2009/Decreto/D6814.htm\#

3 Instrução Normativa RFB no 952, de 2 de julho de 2009. [acesso em 15 set. 2015]. Disponível em: http://normas.receita.fazenda.gov.br/sijut2consulta/link.action?visao= anotado\&idAto $=15916$

4 Lei $n^{\circ} 11.508 / 2007$ [acesso em 15 set. 2015]. Disponível em: http://www.planalto.gov.br /ccivil 03/ ato2007-2010/2007/Lei/L11508.htm.

5 Lei $n^{\circ}$ 11.732/2008. [acesso em 15 set. 2015]. Disponível em: http://www.planalto.gov. br/ccivil_03/_ato2007-2010/2008/Lei/L11732.htm

6 Portaria ALF/PCE n 38, 20 de outubro de 2015. [acesso em 15 set. 2015]. Disponível em: http://www.mdic.gov.br/arquivos/dwnl_1432650840.pdf

7 Portaria RFB n 3.518/2011. [acesso em $\overline{15}$ set. 2015]. Disponível em: http://normas. receita.fazenda.gov.br/sijut2consulta/link. action?idAto $=36460 \& v i s a o=0$ riginal Portaria 20, de 12 de dezembro de 2014 